\title{
Deficient acquisition and retention of single-alternation go, no-go in rats with medial thalamic lesions*
}

\author{
LARRY W. MEANS, MARVIN W. HUNT, R. REID WHITESIDE, and THOMAS W. BATES \\ East Carolina University, Greenville, North Carolina 27834
}

\begin{abstract}
Two experiments were conducted to examine the effects of lesions of the dorsomedial area of the thalamus (DMT) in female Long-Evans rats on both preoperative acquisition and postoperative retention of a preoperatively acquired operant, single-alternation, go, no-go task. In the first experiment, a group of eight rats with bilateral DMT lesions were found to be deficient on postoperative acquisition relative to a group of eight control-operated animals. In the second experiment, a group of seven rats with DMT lesions showed deficient postoperative retention of the preoperatively acquired response relative to a group of eight control-operated animals.
\end{abstract}

Research with several species has produced evidence that damage to the dorsomedial area of the thalamus (DMT) results in acquisition and retention deficits (see Delacour, 1971; Vanderwolf, 1971; Victor, Adams, \& Collins, 1971). For example, monkeys with total destruction of the dorsomedial nucleus of the thalamus (DMN) are deficient on visual discrimination and delayed response tasks (Schulman, 1964), cats with lesions of the DMT are deficient on complex maze problems (Warren \& Akert, 1960) and avoidance (Ingram, 1958), and rats are deficient on avoidance (Delacour, 1971; Vanderwolf, 1971), shock-motivated brightness discrimination (Thompson \& Massopust, 1960), two-bar alternation (Gross, Chorover, \& Cohen, 1965), and complex mazes (Delacour, Albe-Fessard, \& Lebouban, 1966; Gross et al, 1965). Recently, rats with large medial thalamic lesions have also been found to be deficient on acquisition and postoperative retention of a preoperatively acquired maze, visual-tactile, compound stimulus, discrimination task (Means et al, in press). Rats with DMT lesions are not deficient on simple approach responses for food or water, barpress responses (Dantzer \& Delacour, 1972; Vanderwolf, 1962, 1971), or autonomic responses in avoidance situations (Delacour \& Santacana, 1967; Vanderwolf, 1962).

The purpose of the present study was to examine the effects of DMT lesions on a relatively complex task on which rats with lesions of the hippocampus, a structure implicated in acquisition and retention in humans (Milner, 1970) and response inhibition in infrahumans (Douglas, 1967; Kimble, 1968), have shown facilitated acquisition (Means, Walker, \& Isaacson, 1970; Walker, Means, \& Isaacson, 1970; Walker et al, 1972). Specifically, the study was an attempt to determine whether rats with DMT lesions were also facilitated or disrupted relative to control animals on the task. Thus, two studies were conducted to examine the effects of

*Supported by Grants 71A30 and 72A 1 from North Carolina Mental Health to Larry W. Means. The authors gratefully acknowledge the assistance of Henry Hooks and the most helpful comments of Belinda Broome.
DMT lesions on an operant single-alternation, go, no-go task. In the first experiment, DMT-damaged and control-operated rats were tested on acquisition of the alternation task. In the second experiment, two comparable groups were trained on the alternation task preoperatively and given a postoperative reacquisition-retention test.

\section{GENERAL METHOD}

\section{Subjects}

Thirty-one female Long-Evans rats weighing between 179 and $305 \mathrm{~g}$ at the time of surgery were used as Ss. The animals were housed individually with a 14 -h light and 10-h dark cycle. All animals were maintained at $85 \%$ of their ad lib weights and were fed approximately $20 \mathrm{~min}$ after their daily testing session. Water was available in the home cage continuously.

\section{Apparatus}

All behavioral testing was conducted in three identical operant chambers that are $23 \times 21 \times 20 \mathrm{~cm}$. Each chamber has two levers mounted on one end, $7 \mathrm{~cm}$ above the grid floor. Only the left lever was used in the present study. The food magazine is located between the levers, $3 \mathrm{~cm}$ above the floor.

\section{Surgical and Histological Procedures}

During surgery, all rats were anesthestized with sodium pentobarbital $(40 \mathrm{mg} / \mathrm{kg})$ and given $.15 \mathrm{~cm}^{3}$ Bicillin. Animals evidencing labored breathing during surgery were also given $.15 \mathrm{~cm}^{3}$ atropine sulfate. Fourteen animals received lesions centered on the DMN. The coordinates used for the experimental animals were $1.0 \mathrm{~mm}$ behind bregma, $1.0 \mathrm{~mm}$ lateral to the midline, and $6.5 \mathrm{~mm}$ below the top surface of the skull (Pellegrino \& Cushman, 1967). The lesions were produced by passing $2.0 \mathrm{~mA} \mathrm{dc}$ through stainless steel electrodes, insulated with Epoxylite except for the tip, for $12 \mathrm{sec}$. The coordinates for the control-operated animals were the same as those for the experimental rats, except that the electrode was lowered only $5.0 \mathrm{~mm}$ below the surface of the skull to avoid penetrating the thalamus.

Upon completion of behavioral testing, all experimental animals and several control-operated rats were sacrificed with an overdose of sodium pentobarbital and intracardially perfused with saline and then Formalin. The brains were removed, frozen, and sectioned at 50 microns. Every fourth section throughout 


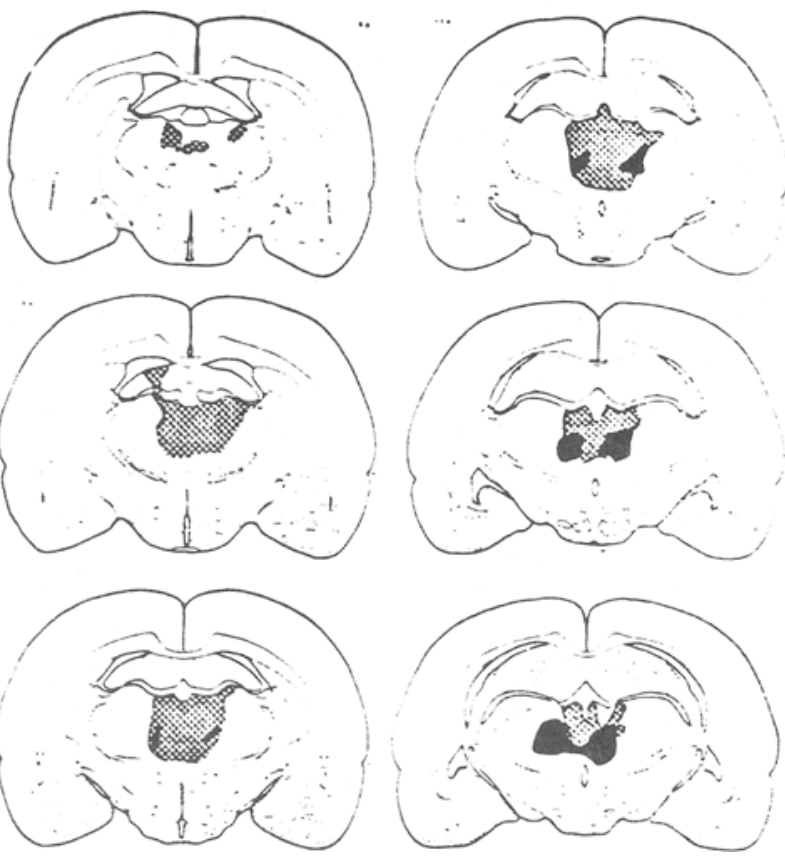

Fig. 1. Reconstructions of the largest and smallest lesions.

the extent of the lesion, or the electrode track in the case of the control operates, was stained with thionin. The slides were then projected onto plates from the Pellegrino and Cushman (1967) stereotaxic atlas so that the extent and locus of lesion could be determined. Reconstructions of the largest and smallest lesions are shown in Fig. 1. In general, the lesions were centered on the DMN and confined primarily to structures of the DMT. Besides extensive bilateral damage to the DMN, the following structures sustained some bilateral damage in most experimental Ss: nucleus parafascicularis, medial and lateral habenularis. paraventricular nucleus, fasciculus, and stria medularis. A few animals had slight, and usually unilateral, damage to structures of the lateral and ventral thalamus. As will be shown below, there was so little variability in the performance of the experimental animals in the two experiments that no effort was made to correlate structural damage with performance.

\section{Behavioral Testing}

All animals were given magazine training and then shaped to press the lever. They were then given 20 -min sessions on CRF until 500 responses were accumulated. Next, all animals were given one CRF session during which they were allowed to make 50 responses. The houselight was on during the shaping and CRF training.

The single alternation training was initiated on the day following completion of the CRF training. Each animal received 20 trials per day. A trial consisted of a $20-\mathrm{sec}$ period, during which the houselight was on, and was followed by a 10-sec intertrial interval. during which the houselight was off. All barpresses made on odd-numbered trials were reinforced with a 45-mg Noyes pellet. Responses made during the intertrial intervals or even-numbered trials were not reinforced. The dependent variables were the latency to the first press and the total number of presses during each reinforced and nonreinforeed trial. The two dependent variables were converted to ratios such that the ratios decreased as the Ss' performance improved. Thus. the latency ratio was the total number of seconds to the first press on each of the 10 reinforced trials of a daily session divided by the total number of seconds to the first press on each of the nonreinforced trials. The response ratio was defined as the total number of presses made during the 10 nonreinforced trials divided by the total number of presses made during the reinforced trials. Also, the number of responses made during the intertrial interval was recorded. These procedures are essentially the same as were used to test animals with lesions of the hippocampus (Means et al, 1970). except that the lever was not retracted during the intertrial interval in the present study.

\section{EXPERIMENT I: ACQUISITION}

A group of eight rats with DMT lesions (DMT-Acq) and a group of eight rats with control operations (C-Acq) were included in the acquisition experiment. All animals were subjected to surgery and then allowed to recuperate for 14 days. Behavioral training was initiated on the 14th day. Upon completion of CRF training, all rats were trained on the single-alternation, go, no-go task for either 30 days (600 trials) or until they attained criterion, whichever occurred first. An animal was considered to have attained criterion when both its latency and response ratios were less than .50 for 3 consecutive days.

\section{Results}

The results of the acquisition experiments are shown in Table 1. Note that all eight rats in the DMT-Acq group failed to attain criterion within the allowed 30 sessions, whereas all C-Acq rats attained criterion in 16 or fewer sessions. To understand the deficit more fully, the two groups were compared on the scores that contribute to the latency and response ratios that were used to determine criterion performance. Table 1 shows the median and range of the mean number of responses and the mean latency to the first press on both go and no-go trials for the last three acquisition sessions for all rats in both groups. Note that with respect to latency, the DMT-Acq groups responded more slowly on go trials

Table 1

Median and Range of Number of Sessions to Latency-Response Criterion and of the Mean Number of Responses and Mean Latency to First Press on Go and No-Go Trials for the Last Three Sessions for the DMT-Acq and C-Acq Animals

\begin{tabular}{|c|c|c|c|c|c|c|c|c|c|c|}
\hline \multirow[b]{3}{*}{ Group } & \multirow{2}{*}{\multicolumn{2}{|c|}{$\begin{array}{l}\text { Sessions to } \\
\text { Criterion }\end{array}$}} & \multicolumn{4}{|c|}{ Latency } & \multicolumn{4}{|c|}{ Responses } \\
\hline & & & \multicolumn{2}{|c|}{ Go Trials } & \multicolumn{2}{|c|}{ No-Go Trials } & \multicolumn{2}{|c|}{ Go Trials } & \multicolumn{2}{|c|}{ No-Go Trial } \\
\hline & $M d n$ & Range & Mdn & Range & Mdn & Range & Mdn & Range & Mdn & Range \\
\hline DMT-Acq & $30^{*}$ & $30-30$ & 7.1 & $2.5-11.5$ & 9.5 & $4.8-12.7$ & 3.6 & $2.3-9.3$ & 1.6 & $1.1-3.9$ \\
\hline C-Acq & 9 & $5-16$ & 3.6 & $2.2-6.2$ & 12.9 & $8.4-16.0$ & 5.6 & $4.7-6.7$ & 1.4 & $.5-2.3$ \\
\hline
\end{tabular}

*Animals failing to attain criterion in 30 sessions were assigned a score of 30 . 
Table 2

Median and Range of Number of Sessions to Latency-Response Criterion Pre- and Postoperatively and of Percent Savings for the DMT-Ret and C-Ret Animals

\begin{tabular}{|c|c|c|c|c|c|c|}
\hline \multirow[b]{3}{*}{ Group } & \multicolumn{4}{|c|}{ Sessions to Criterion } & & \\
\hline & \multicolumn{2}{|c|}{ Preoperative } & \multicolumn{2}{|c|}{ Postoperative } & \multicolumn{2}{|c|}{ Percent Savings } \\
\hline & Median & Range & Median & Range & Median & Range \\
\hline DMT-Ret & 9 & $3-15$ & $20^{*}$ & $1-20 \dagger$ & -122 & $-567-89$ \\
\hline
\end{tabular}

*Animals failing to attain criterion in the allowed 20 sessions were assigned a score of 20.

fOnly one animal in the DMT-Ret group attained criterion performance postoperatively.

$(\mathrm{U}=11, \mathrm{p}<.02)$ and faster on no-go trials $(\mathrm{U}=11$, $\mathrm{p}<.02)$ than rats in the C-Acq group. Thus, the elevated latency ratio of the DMT-Acq group was due to both slow responding on go trials and an inability to withhold responding on no-go trials. The results are essentially the same with respect to the total responses made on go and no-go trials. The DMT-Acq made fewer responses on go trials $(\mathrm{U}=1, \mathrm{p}<.001)$ and more responses on no-go trials $(\mathrm{U}=15.5, \mathrm{p}<.05)$ than the $\mathrm{C}$-Acq group. Therefore, relative to the C-Acq group, the DMT-Acq group was deficient on all four response measures. Finally, the DMT-Acq and C-Acq groups made a mean of 2.1 and 1.7 responses, respectively, during each 10 -sec intertrial on the last three acquisition sessions, a difference which is not significant $(U=21.5, p>.05)$.

\section{EXPERIMENT II: RETENTION}

In the retention experiment, the control-operated (C-Ret) and experimental (DMT-Ret) groups were trained preoperatively and tested postoperatively using a reacquisition procedure. Thus, seven DMT-Ret and eight C-Ret rats were given CRF training followed by go, no-go training. On the day after an animal attained criterion, surgery was performed and it was allowed to recuperate. On the 14th postoperative day, each animal began retraining on the go, no-go alternation task. Each animal was given either 20 postoperative training sessions (400 trials) or trained to criterion, whichever occurred first. The same criterion as was used in the acquisition experiment was employed in the retention experiment. A savings score was determined for each animal using the following formula:

$$
\% S=\left(\frac{O-R}{0}\right) 100
$$

where $S=$ savings, $0=$ sessions to criterion during preoperative training, and $R=$ sessions to criterion during postoperative training.

\section{Results}

The results of the retention experiment are very similar to those of the acquisition experiment. Only one of seven animals in the DMT-Ret group reattained criterion postoperatively in the allowed 20 sessions, while all eight of the animals in the C-Ret group reattained criterion in eight or fewer sessions (see Table 2). While the two retention groups did not differ on sessions to criterion preoperatively, only one rat in the DMT-Ret group showed positive savings while five of eight animals in the C-Ret group showed $100 \%$ savings.

Table 3 shows the median and range of the mean latency and response scores of the animals in both retention groups for their last three postoperative sessions.

Mann-Whitney tests revealed that the DMT-Ret group had a shorter latency on no-go trials than the C-Ret group $(U=9, p<.02)$. The two groups did not differ on go trial latencies $(U=14, p<.05)$. On the response measures, the DMT-Ret group made fewer responses on go trials $(U=9.5, p<.02)$ and more responses on no-go trials $(U=10, p<.02)$ than did the $C$-Ret group. Thus, the failure of the DMT-Ret group to attain criterion postoperatively was due to excessive barpressing on no-go trials and a faiiure to press frequently on go trials. Also, the DMT-Ret animals failed to withhold their first response on no-go trials. The two groups did not differ on the number of ITI responses made during their last three sessions.

The one $S$ in the DMT-Ret group that did attain criterion postoperatively was found to have only about

Table 3

Median and Range of the Mean Number of Responses and Mean Latency to the First Response on Go and No-Go Trials for the Last Three Postoperative Sessions for the DMT-Ret and C-Ret Animals

\begin{tabular}{|c|c|c|c|c|c|c|c|c|}
\hline \multirow[b]{3}{*}{ Group } & \multicolumn{4}{|c|}{ Latency } & \multicolumn{4}{|c|}{ Responses } \\
\hline & \multicolumn{2}{|c|}{ Go Trials } & \multicolumn{2}{|c|}{ No-Go Trials } & \multicolumn{2}{|c|}{ Go Trials } & \multicolumn{2}{|c|}{ No-Go Trials } \\
\hline & Median & Range & Median & Range & Median & Range & Median & Range \\
\hline DMT-Ret & 4.7 & $2.6-9.1$ & 10.2 & $6.2-14.6$ & 3.8 & $1.7-7.1$ & 2.1 & $1.3-4.7$ \\
\hline C-Ret & 3.0 & $2.0-5.7$ & 12.4 & $9.2-16.7$ & 5.5 & $4.9-8.9$ & .8 & $.5-1.5$ \\
\hline
\end{tabular}


$25 \%$ damage to the DMN on one side. while the other side was totally destroyed. All the other experimental animals that failed to attain criterion postoperatively had extensive bilateral damage of the DMN.

\section{DISCUSSION}

The results clearly demonstrate that bilateral DMT lesions centered on the DMN produce deficits on both postoperative acquisition and postoperative retention of a preoperatively acquired, go, no-go, single-alternation response. The DMN-damaged rats were disrupted relative to the control-operated animals on essentially all indices of the alternation response. The deficient latency scores of the experimental animals showed that they were unable to discriminate between go and no-go trials. The poor response scores revealed that having failed to make the discrimination for the first response of each trial, the experimental rats were also relatively limited in their ability to respond appropriately for the remainder of the trial.

The results of the present experiment are consistent with the finding that large medial thalamic lesions produce severe deficits on both postoperative acquisition and postoperative retention of a preoperatively acquired compound-stimulus maze discrimination (Means et al, in press). Medial thalamic lesions apparently disrupt acquisition and retention on both of these appetitive tasks.

The one DMT-Ret animal that demonstrated postoperative retention and was subsequently found to have total DMN destruction on one side but only $25 \%$ DMN destruction on the other side suggests that bilateral DMN destruction is necessary to produce the deficits. However, the effects of unilateral thalamic lesions should be examined before any conclusions are made concerning their behavioral effects.

The results of the present experiment are also consistent with those of other investigators reporting avoidance and complex maze deficits (see Delacour, 1971; Vanderwolf, 1971) in rats with medial thalamic lesions. It appears that medial thalamic lesions disrupt the acquisition and/or retention of many complex tasks. However, as mentioned earlier, simple operant and approach responses are not significantly affected by medial thalamic lesions (Dantzer \& Delacour, 1972; Vanderwolf, 1962, 1971).

While the clinical literature implicates both the hippocampus (Milner, 1970) and the DMN (Victor et al, 1970) in learning and memory, it appears that animal studies differentiate the two structures with respect to function. The acquisition and retention of many tasks are disrupted by DMT lesions (Delacour, 1971; Vanderwolf, 1971), whereas hippocampal lesions appear more likely to disrupt response inhibition (Douglas, 1967; Kimble, 1968). Also, with respect to go, no-go single alternation, animals with hippocampal lesions are facilitated on acquisition (Means et al, 1970), while animals with DMT lesions show deficient acquisition and retention.

Deficits on learning tasks are difficult to interpret. The avoidance deficits observed in rats sustaining medial thalamic lesions have been attributed to the tendency of thalamically damaged animals to freeze in the presence of aversive stimuli (Delacour, 1971; Vanderwolf, 1971). However, an explanation based on freezing would seem to be unacceptable for explaining deficits on appetitive tasks, as rats with medial thalamic lesions are normally active or hyperactive in nonaversive situations (Means et al, in press; Vanderwolf, 1971). Also, deficits on tasks by rats with medial thalamic lesions are not due to changes in gross motor responses, emotionality, or food consumption (Means et al, in press). Finally, the observed deficit on alternation, a task that does not require the use of external sensory cues, would seem to rule out explanations based on sensory deficits. While the above observations eliminate several potential explanations of the deficit, there are several other explanations which must be considered. The lesion may disrupt some aspect of the associative process such as consolidation or retrieval. Also, the lesion may limit the S's ability to attend to the cues of the task or the lesion may disrupt some central "motor selection" process. Presently, it is impossible to rule out any of these latter alternatives. Hopefully, future research will permit a more adequate description of the dysfunction produced by DMT damage and will allow more precise localization of the thalamic structure or structures associated with the deficit.

\section{REFERENCES}

Dantzer, R., \& Delacour, J. Modification d'un phénoméne de suppression conditionée par une lésion thalomique. Physiology \& Behavior, 1972, 8, 997-1003.

Delacour, J. Effects of medial thalamic lesions in the rat: A review and interpretation. Neuropsychologia, 1971, 9, 157-174.

Delacour, J., Albe-Fessard, K., \& Libouban, S. Rôle chez le rat de deux noyaux thalamiques dans le conditionnement instrumental. Neuropsy chologia, 1966, 4, 101-112.

Delacour, J., \& Santacana, M. P. Rôle due thalamus médian dans l'établissement et le rétention de conditionnements défensifs classiques et instrumentaux. Neuropsychologia, 1967, 5, 237-252.

Douglas, R. J. The hippocampus and behavior. Psychological Bulletin, 1967, 67, 416-442.

Gross, C. G., Chorover, S. L., \& Cohen, S. M. Caudate, cortical, hippocampal, and dorsal thalamic lesions in rats: Alternation and Hebb-Williams maze performance. Neuropsychologia, 1965, 3, 53-68.

Ingram, W. R. Modification of learning by lesions and stimulation in the diencephalon and related structures. In $\mathrm{H}$. H. Jasper, L. D. Proctor, R. S. Knighton, W. C. Noshay, and R. T. Costello (Eds.), Reticular formation of the brain. Boston: Little \& Brown, 1958.

Kimble, D. P. The hippocampus and internal inhibition. Psychological Bulletin, 1968, 70, 285-295.

Means, L. W., Huntley, D. H., Anderson, H. P., \& Harrell, T. H. Deficient acquisition and retention of a visual-tactile discrimination task in rats with medial thalamic lesions. 
Behavioral Biology, in press.

Means, L. W., Walker, P. W., \& Isaacson, R. L. Facilitated single-alternation go, no-go acquisition following hippocampectomy in the rat. Journal of Comparative \& Physiological Psychology, 1970, 72, 278-285.

Milner, B. Memory and the medial temporal regions of the brain. In K. H. Pribram and D. E. Broadbent (Eds.), Biology of memory. New York: Academic Press, 1970.

Pellegrino, L. J., \& Cushman, A. J. A stereotaxic atlas of the rat brain. New York: Appleton-Century-Crofts, 1967.

Schulman, S. Impaired delayed response from thalamic lesions. Studies in monkeys. Archives of Neurology, 1964, 11, 477-499.

Thompson, R., \& Massopust, L. C. The effect of subcortical lesions on retention of a brightness discrimination in rats. Journal of Comparative \& Physiological Psychology, 1960, 53, 488-496.

Vanderwolf, C. H. Medial thalamic functions in voluntary behavior. Canadian Journal of Psychology, 1962, 16, 318-330.

Vanderwolf, C. H. Limbic-diencephalic mechanisms of voluntary movement. Psychological Review, 1971, 78, 83-113.
Victor, M., Adams, R. D., \& Collins, G. H. The Wernicke-Korsakoff syndrome. Philadelphia: Davis, 1971.

Walker, D. W., Means, L. W., \& Isaacson, R. L. The effects of hippocampal and cortical lesions on single alternation go, no-go acquisition in rats. Psychonomic Science, 1970, 21, 29-31.

Walker, D. W., Messer, L. G., Freund, G., \& Means, L. W. Effect of hippocampal lesions and intertrial interval on single-alternation performance in the rat. Journal of Comparative \& Physiological Psychology, 1972, 80, 469-477.

Warren, J. M., \& Akert, K. Impaired problem solving by cats with thalamic lesions. Journal of Comparative \& Physiological Psychology, 1960, 53, 207-211.

(Received for publication February 6, 1973; revision received May 14,1973 ; accepted June 1, 1973.) 